\title{
Taurine-Conjugated Mussel-Inspired Iron Oxide Nanoparticles with an Elongated Shape for Effective Delivery of Doxorubicin into the Tumor Cells
}

\author{
Nimisha Singh, Nadine Millot,* Lionel Maurizi, Gérard Lizard, and Rajender Kumar* \\ Cite This: ACS Omega 2020, 5, 16165-16175 \\ Read Online
}

ACCESS

Џlll Metrics \& More

回 Article Recommendations

Supporting Information

ABSTRACT: Multifunctional iron oxide magnetic nanoparticles, among them nanorods, were prepared with a mussel-inspired polydopamine ( $\mathrm{pDA}$ ) surface coating agent for cancer therapeutics. Taurine, a free sulfur-containing $B$ amino acid, was grafted on the pDA at the iron oxide nanoparticle surface to enhance its biocompatibility and targeted delivery action. Doxorubicin (DOX), an anticancer drug, was loaded on the prepared nanovehicles with an entrapment efficiency of $70.1 \%$. Drug release kinetics were then analyzed using UV-vis and fluorescence spectroscopies, suggesting the $\mathrm{pH}$-responsive behavior of the developed nanovehicle. The developed system was then tested on PC-3 cell lines to check its

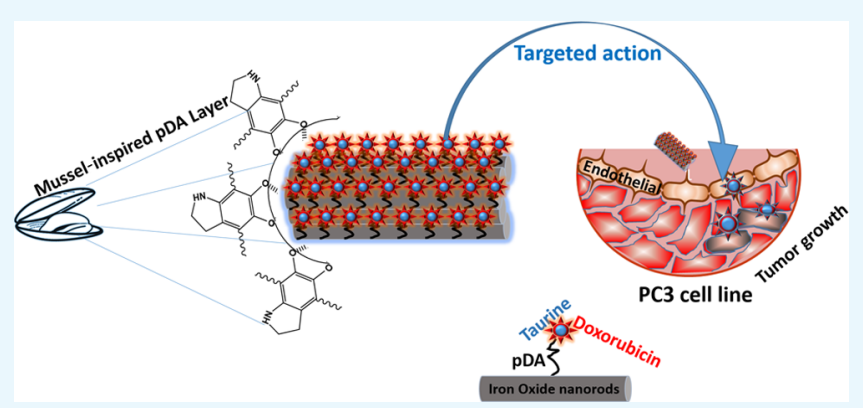
cellular response. Confocal microscopy observations and (3-(4,5-dimethylthiazol-2-yl)-5-(3-carboxymethoxyphenyl)-2-(4sulfophenyl)-2H-tetrazolium) and Annexin V-FITC assays used to evaluate cell toxicity and apoptosis reveal a dose-dependent nature of nanorods and can overcome the side effects of using free DOX with a targeted action.

\section{INTRODUCTION}

Cancer remains the leading cause of fatality in the developed world because of several inducing factors such as environmental pollution and unhealthy living habits. ${ }^{1,2}$ Current therapies require intrusive processes such as surgery to remove a tumor, followed by chemotherapy and/or radiation therapy. These treatments often kill healthy cells and lead to acute toxicity in the patients. ${ }^{3}$ Scientists have made several efforts to improve chemotherapy over 25 years, but an effective regime for cancer treatment is still a distant dream. ${ }^{4}$ One of the essential requirements for the improvement in cancer treatment is drug targeting either by molecular or by physical targeting. ${ }^{5}$ Molecular drug targeting although promising suffers from inherent high cost, immune system activation, and reduced blood residence time. The high blood residence time requires conjugating the drug carrier with polymers, chemical agents, and so forth, which have strong antibiofouling properties, thus preventing the protein carrier interactions and autoimmune response. 6,7 The physical targeting treatment involves the use of magnetic nanocarriers which increase permeability and provide magnetic targeting. ${ }^{8}$ Several magnetic drug carriers based on iron oxide nanoparticles (IONPs) are in use for the cancer drug carriers. ${ }^{9}$ These drug carriers are biocompatible in nature, induce magnetic hyperthermia, and thus reduce the drug resistance of tumor cells. ${ }^{10,11}$ The IONPs thus provide several properties such as magnetic targeting, high blood-residence time, and effective payload of the drug. ${ }^{12}$ The ideal drug carrier which encompasses the above properties besides providing strong anti-biofouling properties and delivers the required payload of the drug at tumor tissue remains a challenge. $^{13}$

Along with surface chemistry, the shapes of these nanostructures play a vital role in deciding the applicability of the developed nanohybrids. ${ }^{14-16}$ A nanostructure dimension within a decided geometrical frame carries a strong determinant of the total cellular uptake. Among different shapes, the rod-shaped nanostructure offers larger uptake than spherical-shaped particles, ${ }^{16,17}$ as it offers two different orientations (long and short axes) that result in providing a different level of control in presenting the drug to targeted sites. ${ }^{18}$ Even the blood half-life also depends on the shape and size of the nanostructure, as shown by rod-shaped micelles having 10 times longer circulation time than that of the spherical micelles. ${ }^{19}$ Research efforts have always been made to achieve small, uniform, and highly dispersed particles. However, recent studies have realized the importance of shape, and thus, one-dimensional structures such as nanorods and nanotubes have come into the picture. ${ }^{20,21}$ Because of their unique properties, we attempt to develop iron oxide

Received: April 16, 2020

Accepted: June 8, 2020

Published: June 23, 2020 
Scheme 1. Schematic Representation Showing the Sequential Modification of Iron Oxide Nanorods: With pDA Leading to pDA- $\mathrm{Fe}_{3} \mathrm{O}_{4}$, Followed by Immobilization of Taurine Leading to T-pDA-Fe $\mathrm{O}_{4}$, Then Loading of Doxorubicin (DOX) Generating DOX-T-pDA-Fe $\mathrm{O}_{4}$ as Anticancer Nanocarriers

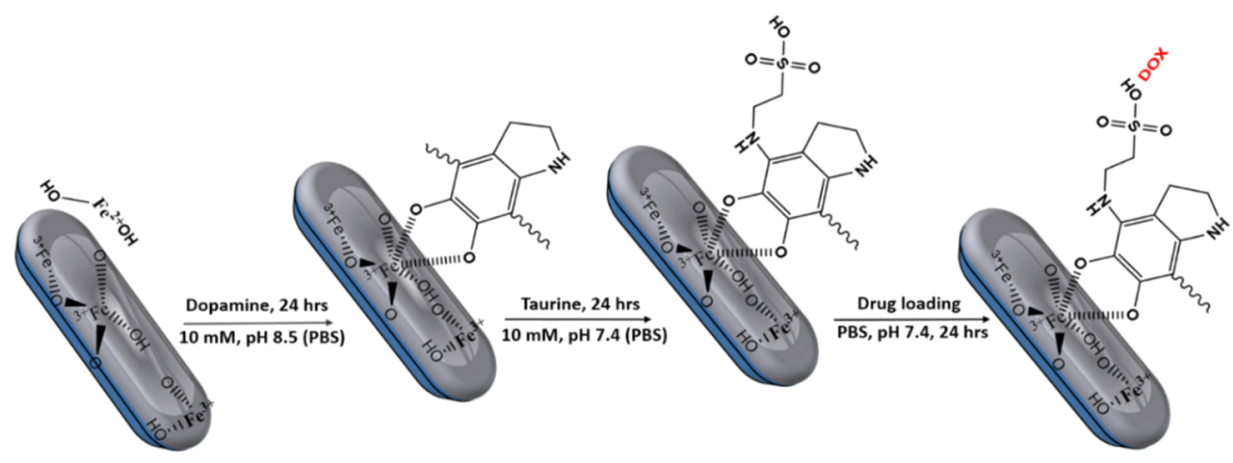

nanorods to explore their diverse applications in the biological field.

Looking over the organic coating, polydopamine (pDA) falls among those anticancer drug delivery systems, ${ }^{22}$ which are biocompatible in nature and possess strong anti-biofouling abilities. ${ }^{23}$ The pDA forms stable coatings on the IONPs by self-polymerization of dopamine (DA) under normal laboratory conditions. pDA-coated IONPs serve as stable anchors to target the anticancer drug ${ }^{24}$ and develop stable drug carriers by providing reactive quinones on the surface for their further modification. ${ }^{25,26}$ Integrating the magnetic property of IONPs and biocompatibility of $\mathrm{pDA}^{27}$ generate excellent nanocarriers for drug delivery in cancer treatment. ${ }^{28}$ Despite these fascinating properties, pDA-based magnetic nanocarriers show limitations in solubility and failed in crossing the blood-brain barrier ${ }^{29,30}$ and thus require further modifications. Besides, surface modification with suitable groups can reduce the protein nanocarrier interaction on the one hand and enhance the blood residence time on the other hand. ${ }^{31}$

To mitigate the problem of the low solubility of $\mathrm{pDA}-\mathrm{Fe}_{3} \mathrm{O}_{4}$ based nanoparticles and to endow the developed nanocarriers, we took the advantage of reactive quinone shells on the pDA$\mathrm{Fe}_{3} \mathrm{O}_{4}$ nanocarrier. The prepared $\mathrm{pDA}-\mathrm{Fe}_{3} \mathrm{O}_{4}$ nanorods were modified by conjugating with amino sulfonic acid taurine. Taurine is a free sulfur-containing $B$ amino acid which is highly soluble in water and can penetrate through the blood-brain barrier. $^{32}$ Taurine offers an advantage when binding with reactive quinones in redox cycling and inhibits the free radical formation. ${ }^{33}$ Thus, conjugating $\mathrm{pDA}-\mathrm{Fe}_{3} \mathrm{O}_{4}$ with taurine serves as a suitable nanocarrier to achieve an efficient drug delivery system for DOX, as DOX alone has several side effects on the cell that can be minimized using these nanocarriers.

Thus, in summary, we developed and studied new multifunctional magnetic nanorods for anticancer drug delivery. Taurine-conjugated nanorods $\left(\mathrm{T}-\mathrm{pDA}-\mathrm{Fe}_{3} \mathrm{O}_{4}\right)$ were characterized, and their physicochemical properties such as drug loading and release of DOX were investigated. The in vitro activity of the designed nanorods was primarily evaluated for its uptake and anticancer activity on human prostate adenocarcinoma PC-3 cells using 3-(4,5-dimethylthiazol-2-yl)5-(3-carboxymethoxyphenyl)-2-(4-sulfophenyl)-2H-tetrazolium (MTS) and Annexin V-FITC assays.

\section{RESULTS AND DISCUSSIONS}

The taurine-functionalized nanorods (T-pDA- $\mathrm{Fe}_{3} \mathrm{O}_{4}$ ) were prepared, as shown in Scheme 1 . The product of coprecipitation is a mixture of small nanoparticles, some larger octahedrally shaped nanoparticles, and nanorods (Figure 1A).
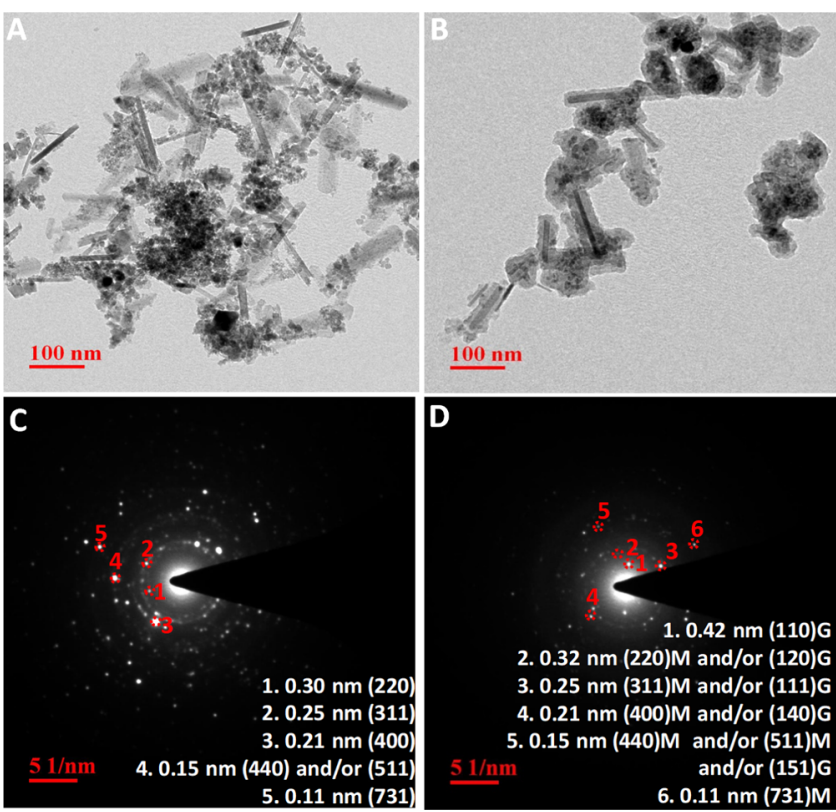

Figure 1. TEM images showing the size of (A) $\mathrm{Fe}_{3} \mathrm{O}_{4}$ nanoparticles and (B) $\mathrm{pDA}-\mathrm{Fe}_{3} \mathrm{O}_{4}$ nanorods with their respective SAED patterns (C) $\mathrm{Fe}_{3} \mathrm{O}_{4}$ nanorods and (D) pDA- $\mathrm{Fe}_{3} \mathrm{O}_{4}$ nanorods, where $\mathrm{G}$ and $\mathrm{M}$ notations are specified for goethite and magnetite structures, respectively.

The transmission electron microscopy (TEM) analysis thus shows that the developed nanorods have an average diameter of $10 \pm 2 \mathrm{~nm}$ and a length of $63 \pm 14 \mathrm{~nm}$, as shown in Figure 1A. Under the conditions applied for the coprecipitation, the goethite nanorods may be obtained as a secondary phase. ${ }^{34}$ To determine the structure of the nanoparticles, selected area electron diffraction (SAED) patterns were analyzed and compared with ICDD collection (01-071-6336 for magnetite and 01-081-0464 for goethite). On observing the lattice points and the intensity of rings formed (Figure 1C), we can confirm that the reported nanorods are of magnetite and not of goethite. All rings can be indexed as those of magnetite, and no goethite formation was observed. Indeed, the maximum intensity observed for goethite was at $0.41 \mathrm{~nm}(110)$, and this ring was not observed in the SAED image (Figure 1C). After pDA grafting, in some parts of the TEM grids, common 
lattice points of the goethite structure (110) were observed, along with the magnetite structure (Figure 1D). Because alkali $\mathrm{pH}$ favors the transformation of goethite from magnetite, ${ }^{35}$ it might support the assumption of goethite traces in the developed rod-like structure forming a mixture containing magnetite and goethite. Additionally, the goethite surface has high surface energy and coarsens more rapidly; thus, causing such transformations is common in precipitation processes. ${ }^{34}$ SAED patterns after pDA grafting were less defined because of the presence of the amorphous organic coating. It may contribute to both hide the crystallographic contribution of small nanoparticles with a magnetite structure and highlight that of big tubes with a goethite structure. Even if the powder is a mixture of magnetite along with few goethite rods, the different nanohybrids obtained were called as pDA- $\mathrm{Fe}_{3} \mathrm{O}_{4}$ nanorods in the context of this paper. After pDA grafting, it should be noted that small spherical-shaped particles of diameter $10 \pm 3 \mathrm{~nm}$ have also been observed overlapping with the nanorods. Other particles maintain their nanorod-like structure with a distinct layer of pDA having a thickness of about $10 \mathrm{~nm}$ (Figure 1B). The small spherical nanoparticles seem entrapped in the pDA layer around nanorods, leading to elongated nanostructures constituted of both nanorods and spherical nanoparticles joined together thanks to pDA. The morphology remains the same after taurine conjugation (data not shown). The energy-dispersive X-ray spectroscopy (EDX) spectra and elemental mapping (Figure S1, Supporting Information and Table 1) confirm the successful conjugation of taurine in $\mathrm{T}-\mathrm{pDA}-\mathrm{Fe}_{3} \mathrm{O}_{4}$ nanorods, as revealed by the strong sulfur signal whose only source is taurine.

Table 1. Elemental Distribution Showing the Composition of Prepared Nanoparticles Using XPS

\begin{tabular}{crcccc} 
& \multicolumn{5}{c}{ Elements (atomic concentration \%) } \\
\cline { 2 - 6 } Samples & \multicolumn{1}{c}{$\mathrm{Fe}$} & $\mathrm{O}$ & $\mathrm{C}$ & $\mathrm{N}$ & $\mathrm{S}$ \\
$\mathrm{Fe}_{3} \mathrm{O}_{4}$ & 12.6 & 42.8 & 44.5 & & \\
$\mathrm{pDA}-\mathrm{Fe}_{3} \mathrm{O}_{4}$ & 2.4 & 27.6 & 64.2 & $\mathbf{5 . 7}$ & \\
$\mathrm{T}-\mathrm{pDA}-\mathrm{Fe}_{3} \mathrm{O}_{4}$ & 0.6 & 26.5 & 64.3 & 6.4 & $\mathbf{2 . 2}$
\end{tabular}

Detailed elemental composition analysis (Table 1) confirms the successful and stepwise functionalization of the prepared elongated nanostructures.

Fourier transform infrared spectroscopy (FT-IR) spectra of the nanostructures show a broadband at $3200 \mathrm{~cm}^{-1}$ because of the vibration of the hydroxyl groups on the surface of the nanorods (Figure 2A). The strong band observed at $1647 \mathrm{~cm}^{-1}$ is due to the $\mathrm{OH}$ deformation modes of the hydroxyl groups and adsorbed water on the surface. ${ }^{36,37}$ pDA- $\mathrm{Fe}_{3} \mathrm{O}_{4}$ nanorods show additional bands, such as $\mathrm{C}-\mathrm{H}$ vibration of catechol at $2523 \mathrm{~cm}^{-1}$ and bands of a primary amine at $3181 \mathrm{~cm}^{-1}$. $^{38}$ The peak at $1461 \mathrm{~cm}^{-1}$ due to the overlapping of $\mathrm{CH}_{2}$ scissoring band with the $\mathrm{C}=\mathrm{C}$ ring stretching band further confirms the formation of pDA layers on $\mathrm{Fe}_{3} \mathrm{O}_{4}$ nanorods. ${ }^{39}$ The additional bands at $2108 \mathrm{~cm}^{-1}$ and $1784 \mathrm{~cm}^{-1}(\mathrm{C}-\mathrm{O}$ ester) are the clear evidence for the successful modification of the nanorods with $\mathrm{DA}^{40} \mathrm{~T}$-pDA- $\mathrm{Fe}_{3} \mathrm{O}_{4}$ nanorods show peaks of sulfones of taurine at $1035 \mathrm{~cm}^{-1}$ and $1178 \mathrm{~cm}^{-1}$ (Figure 2). ${ }^{41}$

The surface composition and nature of bonding in the prepared nanorods were further studied using X-ray photoelectron spectroscopy (XPS). The surface elemental composition from XPS was in conformity with the EDX data (Table 1) where the percentage of carbon and nitrogen increases with each modification. The survey scan of $\mathrm{Fe}_{3} \mathrm{O}_{4}$ nanoparticles shows two strong bands at $724 \mathrm{eV}\left(\mathrm{Fe} 2 \mathrm{p}_{1 / 2}\right)$ and $710 \mathrm{eV}(\mathrm{Fe}$ $\left.2 \mathrm{p}_{3 / 2}\right)$. XPS of $\mathrm{pDA}-\mathrm{Fe}_{3} \mathrm{O}_{4}$ nanorods show an additional peak at $397 \mathrm{eV}$ because of the nitrogen of the $\mathrm{pDA}$ layer on the magnetic core. Nitrogen confirms the successful modification of $\mathrm{Fe}_{3} \mathrm{O}_{4}$ nanorods with pDA molecules on the surface. After the conjugation of taurine to the $\mathrm{pDA}-\mathrm{Fe}_{3} \mathrm{O}_{4}$ nanorods, an additional peak of sulfur at about $167 \mathrm{eV}$ in XPS survey scan (Figure 3) confirms the successful taurine conjugation to form $\mathrm{T}$-pDA- $\mathrm{Fe}_{3} \mathrm{O}_{4}$ nanorods.

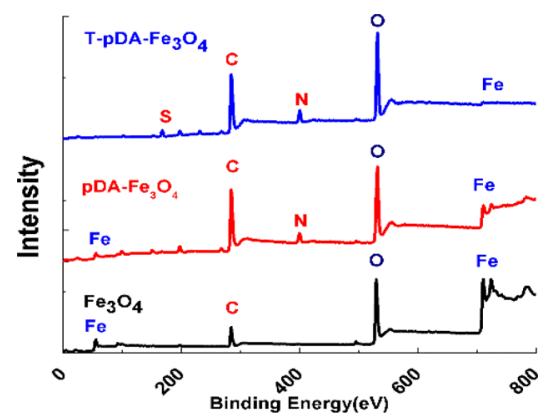

Figure 3. XPS data showing the elemental analysis of synthesized nanoparticles.

$\mathrm{Fe}_{3} \mathrm{O}_{4}$ nanoparticles are a mix valence compounds having a chemical notation of $\left[\mathrm{Fe}^{3+}\right]_{\mathrm{A}}\left[\mathrm{Fe}^{2+} \mathrm{Fe}^{3+}\right]_{\mathrm{B}} \mathrm{O}_{4}$, where the $\mathrm{Fe}^{3+} /$ $\mathrm{Fe}^{2+}$ ratio is supposed to be $2: 1$ and $\mathrm{A}$ is the tetrahedral sublattice and $\mathrm{B}$ is the octahedral one. ${ }^{42}$ The peak-fitted
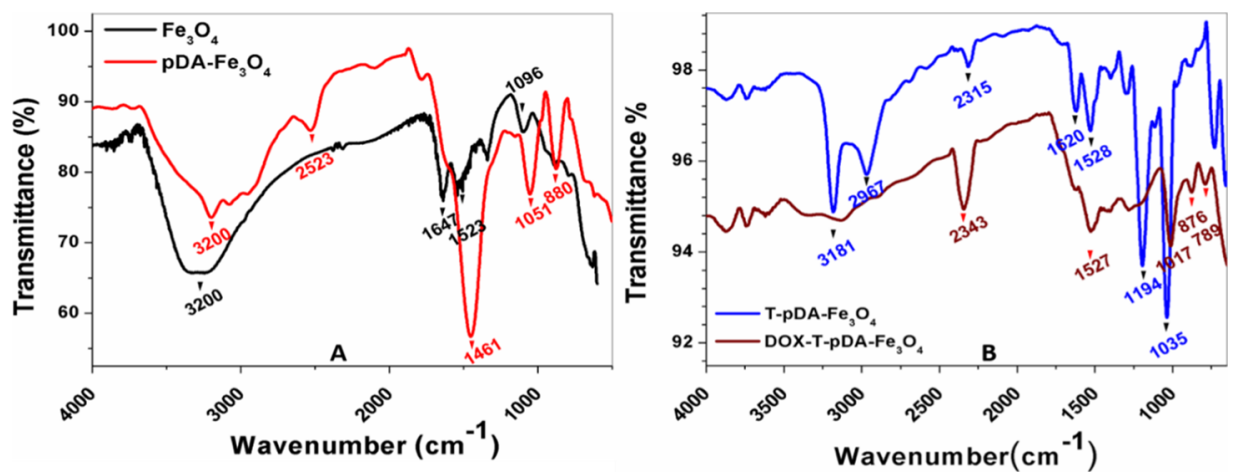

Figure 2. FT-IR spectra of $(\mathrm{A}) \mathrm{Fe}_{3} \mathrm{O}_{4}$ nanoparticles and pDA- $\mathrm{Fe}_{3} \mathrm{O}_{4}$ nanorods and (B) taurine-functionalized nanorods (T-pDA-Fe3O4) without drug and DOX-loaded T-pDA-Fe $\mathrm{O}_{4}$ nanorods. 

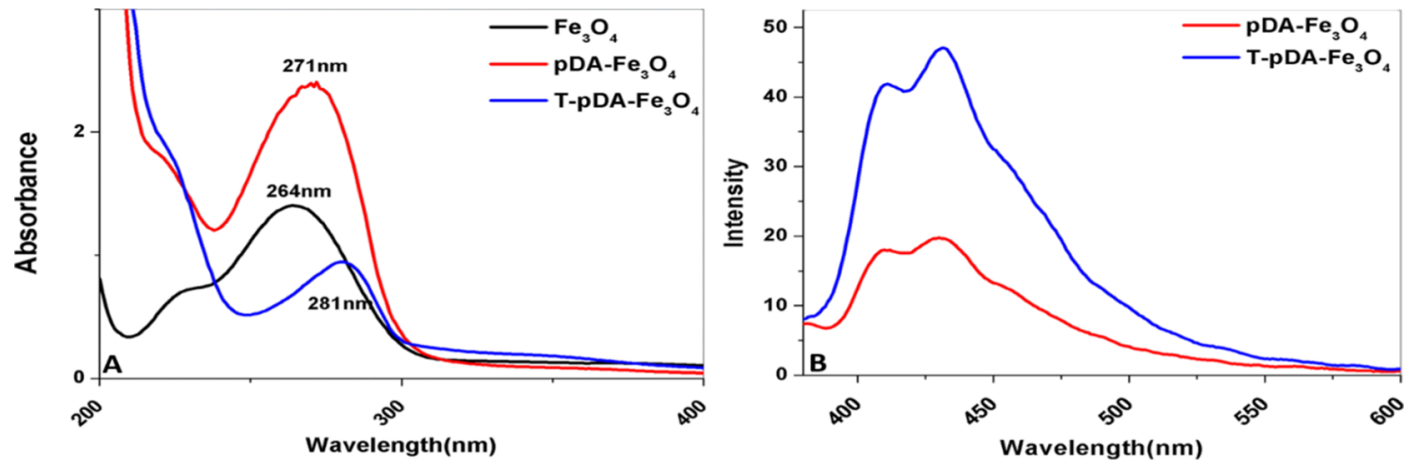

Figure 4. (A) UV-vis spectra showing the absorbance of the prepared nanoparticles and (B) fluorescence emission spectra.
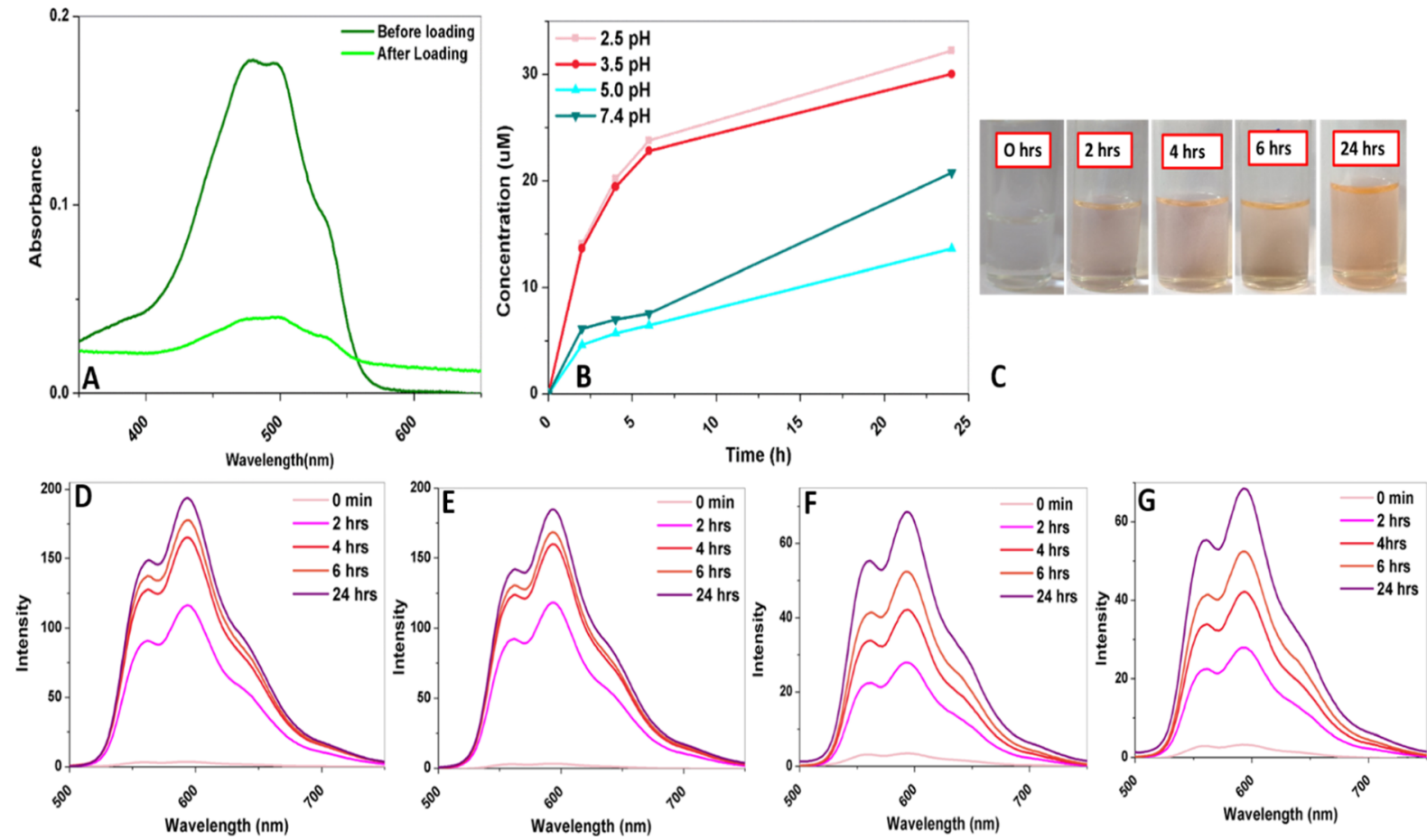

Figure 5. (A) UV-vis spectra showing the drug loading efficiency, (B) release kinetics at different $\mathrm{pH},(\mathrm{C})$ drug release in different time intervals showing the distinct color change, and $(\mathrm{D}-\mathrm{G})$ fluorescence spectra showing the drug release at $\mathrm{pH} 2.5,3.5,5.0$, and 7.4, respectively. The images shown in the figure are of free domain and are used in the experiments to show the color change during the drug release experiments and suspension of the developed nanohybrid after functionalization steps, respectively.

spectra of as-prepared $\mathrm{Fe}_{3} \mathrm{O}_{4}$ nanoparticles show that the $\mathrm{Fe} 2 \mathrm{p}$ core level splits into two components, as shown in Figure S2A, $2 p_{1 / 2}$, and $2 p_{3 / 2}$ because of spin-orbit coupling and two satellite peaks of $\mathrm{Fe}$ (II) $2 \mathrm{p}_{3 / 2}$ at $718.3 \mathrm{eV}$ and $\mathrm{Fe}(\mathrm{III}) 2 \mathrm{p}_{1 / 2}$ at $732.4 \mathrm{eV}$. $^{43}$ The oxidation state of iron species present on the surface of the sample may be evaluated using these XPS data (the penetration depth of XPS analysis is about $3 \mathrm{~nm}$ ). The binding energy difference calculated between $\mathrm{Fe} 2 \mathrm{p}_{3 / 2}$ and its satellite peaks corresponds to the oxidation state of the iron cations; this difference is close to $6 \mathrm{eV}$ for $\mathrm{Fe}^{2+}$ and $8 \mathrm{eV}$ for $\mathrm{Fe}^{3+}$. In our study, this difference is equal to $8.2 \mathrm{eV}$, suggesting the oxidation state of $\mathrm{Fe}^{3+}$ on the surface of the sample. ${ }^{44,45}$

The peak-fitted spectra of oxygen in $\mathrm{Fe}_{3} \mathrm{O}_{4}$ nanoparticles (Figure S2B) show peaks of $\mathrm{Fe}-\mathrm{O}$ and $\mathrm{Fe}-\mathrm{OH}$ at $529.3 \mathrm{eV}$ and $530.2 \mathrm{eV}^{46}$ The peak-fitted spectra of carbon in pDA$\mathrm{Fe}_{3} \mathrm{O}_{4}$ nanorods reveal two major components (Figure S2C) at $284.4 \mathrm{eV}$ for $\mathrm{C}-\mathrm{C}$ and $285.1 \mathrm{eV}$ for $\mathrm{C}-\mathrm{N}$ that suggests the cyclized structure of $\mathrm{pDA}$ on the surface and a weak peak at $287.2 \mathrm{eV}$ for $\mathrm{C}=\mathrm{O}$, indicating the possible tautomers. ${ }^{47}$
Indeed, different mechanisms have been proposed for the polymerization of DA on different surfaces. ${ }^{48-50}$ Thus, subsequent cyclization and oxidation transform the DA into the cyclic structure in pDA which, via covalent aryl linkages, forms continuous pDA layers on the substrate. ${ }^{51,52}$ This can be understood by looking at the atomic percentage of carbon and nitrogen in Table 1, which shows a subsequent increase after coating. Additionally, the nitrogen peak when split into two components (Figure S2D) at $399.6 \mathrm{eV}$ for $\mathrm{R}-\mathrm{NH}_{2}$ and $400.7 \mathrm{eV}$ for $\mathrm{R}-\mathrm{NH}-\mathrm{R}^{47}$ confirms the $\mathrm{pDA}$ on the $\mathrm{Fe}_{3} \mathrm{O}_{4}$ structure and agrees with the reported mechanism of the $\mathrm{pDA}$ formation. ${ }^{29,53}$

The peak-fitted spectra of carbon in T-pDA-Fe $\mathrm{O}_{3}$ (Figure $\mathrm{S} 2 \mathrm{E}$ ) show a pattern similar to those in $\mathrm{pDA}-\mathrm{Fe}_{3} \mathrm{O}_{4}$ unlike the $\mathrm{C} 1 \mathrm{~s}$ region which shows a slight shift in the $\mathrm{C}-\mathrm{N}$ band. Because $\mathrm{C}-\mathrm{N}$ and $\mathrm{C}-\mathrm{S}$ have the same region in the XPS, the presence of sulfur might result in this shifting. The area percentage of $\mathrm{C}-\mathrm{C}$ groups decreases, whereas the $\mathrm{C}-\mathrm{N} / \mathrm{C}-\mathrm{S}$ area percentage increases upon taurine conjugation (Table S1). 
Scheme 2. Conjugation of Doxorubicin Drug onto T-pDA-Fe $\mathrm{O}_{4}$ Nanoparticles Showing a Sulfonamide Bond as pH-Sensitive Facilitating the Release Behavior of Drug
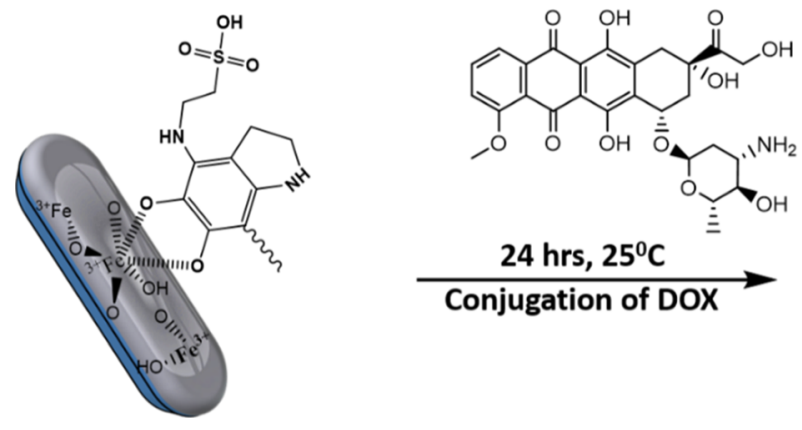

$24 \mathrm{hrs}, 25^{\circ} \mathrm{C}$ Conjugation of DOX

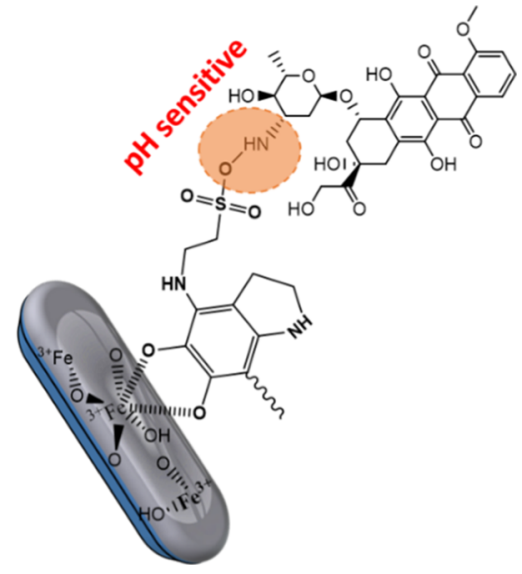

A similar pattern is observed in peak-fitted nitrogen spectra (Figure S2F). Sulfur reveals two components at binding energies of $167.2 \mathrm{eV}$ and $168.0 \mathrm{eV}$ because of $\mathrm{SO}_{3} \mathrm{H}$ and $\mathrm{C}-\mathrm{S}$ bonds whose only source is taurine. All these results suggest the successful bonding of taurine on the surface. ${ }^{54}$

The hydrodynamic diameter and size distribution of the nanorods were estimated from dynamic light scattering (DLS) measurements, as shown in Figure S3. Because DLS measurements are based on spherical models, the data calculated here are not absolute data and allow just to compare samples after each step of the synthesis. Besides this, the size distribution from DLS is in correlation with TEM results because the size of bare $\mathrm{Fe}_{3} \mathrm{O}_{4}$ nanoparticles is $24 \pm 2 \mathrm{~nm}$, which is a mean value between sizes of spherical nanoparticles and sizes of nanorods. The particle size increases with the increase in surface functionalization. Indeed, the DLS size of $\mathrm{pDA}-\mathrm{Fe}_{3} \mathrm{O}_{4}$ nanorods was measured to be $91 \pm 2 \mathrm{~nm}$ and that of $\mathrm{T}$-pDA- $\mathrm{Fe}_{3} \mathrm{O}_{4}$ nanorods was measured to be $122 \pm 1 \mathrm{~nm}$.

The UV-vis spectra of as-prepared nanorods (Figure 4A) show absorption at $264 \mathrm{~nm}, 271 \mathrm{~nm}$, and $281 \mathrm{~nm}$ for $\mathrm{Fe}_{3} \mathrm{O}_{4}$, pDA- $\mathrm{Fe}_{3} \mathrm{O}_{4}$, and $\mathrm{T}-\mathrm{pDA}-\mathrm{Fe}_{3} \mathrm{O}_{4}$ nanorods. The absorption of $\mathrm{Fe}_{3} \mathrm{O}_{4}$ nanoparticles is due to the charge-transfer bands of $\mathrm{Fe}^{3+} / \mathrm{Fe}^{2+}$ complexes. ${ }^{55,56}$ Also, peaks in this region might be due to the $d$ to $d^{*}$ transitions in DA. ${ }^{56}$ The polymerization reaction of DA to $\mathrm{pDA}$ is a complicated process and shows different absorbances for different intermediate structures in between. ${ }^{57}$ The UV-visible spectra of $\mathrm{pDA}-\mathrm{Fe}_{3} \mathrm{O}_{4}$ nanorods show the leucodopaminochrome type of structure which is UV transparent. If the polymerization reaction had proceeded through the full oxidation process resulting in a dopaminochrome structure, there would have been a strong absorbance band observed at around $400 \mathrm{~nm}$, which is the characteristic band of a quinone. ${ }^{58}$

T-pDA- $\mathrm{Fe}_{3} \mathrm{O}_{4}$ nanorods show a shift in absorbance from 271 $\mathrm{nm}$ to $281 \mathrm{~nm}$, that is, blue to a red shift, which suggests the presence of the taurine molecule in the pDA moiety. Besides having excellent biocompatibility and physicochemical properties, pDA also shows fluorescence properties in actual analysis and detection. ${ }^{59}$ The fluorescence spectra of the pDA- $\mathrm{Fe}_{3} \mathrm{O}_{4}$ and $\mathrm{T}$-pDA- $\mathrm{Fe}_{3} \mathrm{O}_{4}$ nanorods (Figure $4 \mathrm{~B}$ ) show an increase in the fluorescence intensity upon taurine conjugation to $\mathrm{pDA}$ $\mathrm{Fe}_{3} \mathrm{O}_{4}$ nanorods because of the presence of the sulfonic group in taurine. ${ }^{60}$ The low fluorescence intensity of $\mathrm{pDA}$ is due to fluorescent precipitates from the oxidation of DA. ${ }^{61}$ In $\mathrm{pDA}$, the extended $\pi-\pi$ stacking interaction induces the fluorescence quenching; a hydroxyl group can prevent that. ${ }^{62-64}$ Thus, taurine on the surface enhances the fluorescence of the nanohybrid by blocking the $\pi-\pi$ stacking on account of the presence of sulfonic groups. ${ }^{59}$

2.1. Drug Loading and Release Study. One of the most important parameters in designing a nanocarrier is to understand the entrapment/loading efficiency of the chosen drug. Because higher drug loading has greater effects on drug release rates, ${ }^{65}$ the entrapment efficiency of the developed system has been calculated as $70.1 \%$ from UV-vis spectroscopy, as shown in Figure 5, using a reported method. ${ }^{66}$ High DOX loadings were observed in the developed system because of the strong covalent bond between the sulfonic head group of functionalized nanoparticles and the amine of the DOX molecule (Scheme 2), thereby providing a better association of drug with the surrounding taurine shell acting as a drug reservoir and also making it as a $\mathrm{pH}$-sensitive sulfonamide linkage as explained by Kang et al., in which they showed that the ionization of the sulfonamide bond as a function of $\mathrm{pH}$ results in the aggregation of the polymers and hydrogel. ${ }^{67,68}$ Additionally, the aromatic ring on the drug molecule further facilitates the drug loading capacity by using the delocalized $\pi$ electrons via hydrophobic interaction and $\pi-\pi$ stacking. ${ }^{69}$ To further ensure the bonding nature of DOX, FT-IR confirms the successful loading into the nanorods with the presence of a sulfonamide peak observed at $3200 \mathrm{~cm}^{-1}$ (Figure 2B), suggesting the covalent bonding of the DOX molecule, as can also be depicted in Scheme 2. ${ }^{70}$ Other strong peaks for the DOX structure were observed at $1017 \mathrm{~cm}^{-1}$ for $\mathrm{C}-\mathrm{O}$ vibration and $1527 \mathrm{~cm}^{-1}$ for bending vibration of the $\mathrm{C}-\mathrm{H}$ ring structure, ensuring the loading of $\mathrm{DOX}$ into T-pDA- $\mathrm{Fe}_{3} \mathrm{O}_{4}$ nanorods. ${ }^{71}$

Drug release studies were then performed in both neutral

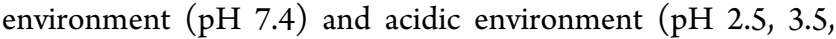
and 5.0) at $37^{\circ} \mathrm{C}$ to establish the feasibility of the developed drug delivery vehicle. Release study investigated using UV-vis and fluorescence spectroscopy (Figure 5B,D-G) suggests the $\mathrm{pH}$-responsive behavior of drug release, where the amount of drug release was more important in acidic $\mathrm{pH}$ compared to that in neutral $\mathrm{pH}$.

The concentration of the released drug (Figure 5B) at $\mathrm{pH}$ 2.5 was $24 \mu \mathrm{M}$, whereas at $\mathrm{pH} 7.4$, it was $8 \mu \mathrm{M}$ within first $6 \mathrm{~h}$. Conclusively, the maximum release was observed in acidic $\mathrm{pH}$ 
range (2.5 and 3.5) with $30 \mu \mathrm{M}$ DOX released in $24 \mathrm{~h}$. When the medium shifts toward alkaline $\mathrm{pH}$, the release rate decreased because of an initial burst of the drug. We can attribute this to the reduced binding capacity of the drug, followed by slower release rates in the alkaline environment. ${ }^{12}$ The abrupt release of drug in the acidic environment can be due to the disruption of the sulfonic linker in the acidic condition where the sulfonamide linkage is known to be the $\mathrm{pH}$-sensitive ${ }^{68}$ that influences in the rapid release of DOX into the medium. ${ }^{73}$ The literature suggests that there are various modes of delivery which are responsible to trigger the release of drug by altering the parameters (linkage, $\mathrm{pH}$, temperature, etc.); in our study, we observed that it is the sulfonamide linkage playing its role in the drug release mechanism. ${ }^{74}$ Therefore, it suggests $\mathrm{pH}$-dependent DOX release which offers a great advantage in the applicability of developed nanohybrids in treating cancer cells. Because the extracellular matrix of tumors in vivo is acidic $(\mathrm{pH}<7)$ when compared to the microenvironment of normal cells which is neutral, the $\mathrm{pH}$ difference thereby favors the dissolution of DOX, facilitating the drug release in the tumor. ${ }^{75,76}$

2.2. Cytotoxicity Studies Were Performed To Study the Suitability of Developed Nanorods. Cytotoxicity studies were performed to study the suitability of developed nanorods on PC-3 cells to explore the usage of DOX in treating prostate cancer along with haematological or solid tumors. Thus, MTS assay and Annexin V FITC apoptosis assay were performed for the cytotoxic evaluation of the developed nanohybrids. The results of the MTS assay performed on PC-3 cell lines as a percent of cell survived versus the concentration of drug loaded are shown in Figure 6.

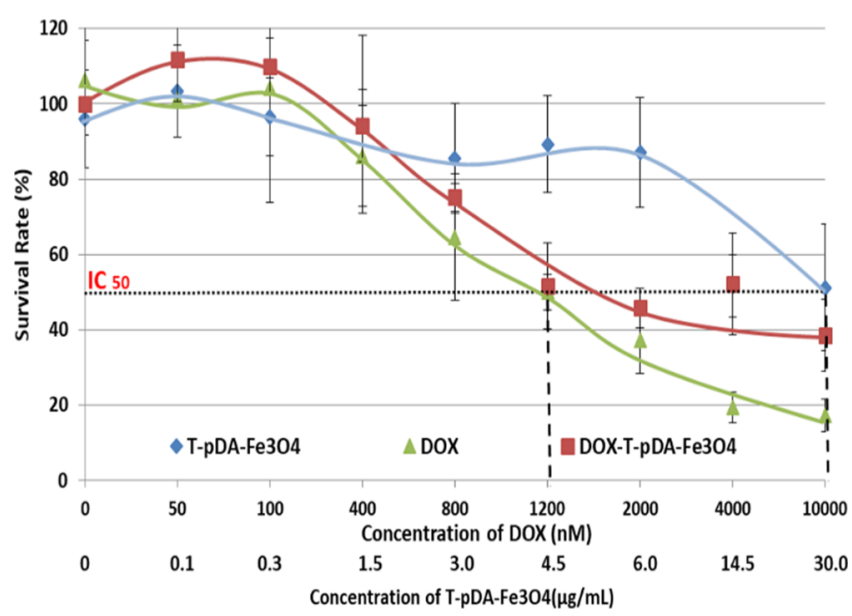

Figure 6. MTS assay showing the percent of cell survival against the various concentrations of the drug when incubated for $48 \mathrm{~h}$.

The cytotoxicity of DOX-loaded nanorods was compared with that of the free drug and with that of T-pDA- $\mathrm{Fe}_{3} \mathrm{O}_{4}$ without DOX (same concentrations of nanohybrids, i.e., here values of $\left[\mathrm{T}-\mathrm{pDA}-\mathrm{Fe}_{3} \mathrm{O}_{4}\right]$ in the range $0.1 \mu \mathrm{g} / \mathrm{mL}-30 \mu \mathrm{g} / \mathrm{mL}$ ). DOX-loaded nanoparticles and free DOX share a similar trend where the $I C_{50}$ value for free DOX was observed at $1200 \mathrm{nM}$ and for DOX-loaded nanoparticles was observed at $1500 \mathrm{nM}$.

Compared to nanorods without DOX, the drug-loaded nanorods show higher cytotoxicity as can also be seen in the confocal images (Figure 7). On comparing DOX as control with $\mathrm{T}-\mathrm{pDA}-\mathrm{Fe}_{3} \mathrm{O}_{4}$ loaded with DOX from the images, the cells show abrupt changes in their morphology and the cell peripheral looks distorted in the presence of nanoparticles. Drug penetration can be easily observed, as shown in Figure $7 \mathrm{C}$, in confocal images, with some accumulation of the particle. The images suggested comparable cellular uptake with slight aggregation because of the higher affinity of amine to the sulfonic group of the nanorods, ${ }^{77}$ though the drug internalization observed is less because of the lower concentration of the nanocarrier.

However, this observation was in correlation with flow cytometry results. Indeed, at higher concentration, the DOXloaded nanorods show $61.4 \pm 9.5 \%$ cell death, while free DOX shows $82.8 \pm 4.3 \%$ at the highest studied concentration. This suggests that DOX-loaded nanorods result in similar cytotoxic results, which can help to overcome side effects on using free DOX for the cancer treatment.

PC-3 cells were incubated for $24 \mathrm{~h}$, stained by Annexin VFITC and propidium iodide (PI), and analyzed by flow cytometry with the nanorod concentration of $0.5 \mu \mathrm{g} / \mathrm{mL}$. Flow cytometry (Figure 8) is divided into four regions, which defines the cell death. The $Q_{1}$ quadrant represents unviable cells (PI positive and annexin negative). The $\mathrm{Q}_{2}$ quadrant represents cells that are in late apoptosis or necrosis (both annexin and PI positive). The Q3 quadrant represents viable cells (both Annexin-FITC and PI negative). The Q4 quadrant represents cells in early apoptosis (annexin positive and PI negative), ${ }^{78}$ which suggests that nanorods induced cell apoptosis.

The cell death in the early apoptotic region for the nanorods was $15.6 \%$, whereas for DOX-loaded nanorods, the cell death was $25.6 \%$. This increase in cell death in $24 \mathrm{~h}$ was significant to treat prostate cancer. However, when free DOX was checked for the cytotoxicity, the cell death was $26.8 \%$ which is similar to the DOX-loaded nanorods. Thus, the developed nanocarrier offers a similar trend, as was observed in the MTS assay for 48 $\mathrm{h}$ of study. However, on observing the $\mathrm{Q}_{2}$ phase, there is no significant increase in the late apoptotic region; it suggests that most of the target cells recognized by effector cells die via the apoptosis pathway, and the cell death was observed in the very first 4-6 $\mathrm{h}$ and so maximum cell population was observed in the early apoptotic region. This was in very well agreement with the drug release observed in UV-vis spectroscopic calculation where the drug shows maximum release within 4-6 $\mathrm{h}$, followed by $24 \mathrm{~h}$. The biological study suggests that the developed nanorods are nontoxic compared to free DOX to the normal cells and can be effectively used to treat the cancer cells. The results were similar to the MTS assay where the $\mathrm{IC}_{50}$ value was $0.75 \mu \mathrm{g} / \mathrm{mL}$ for $48 \mathrm{~h}$ of incubation. Thus, $5 \mu \mathrm{g} / \mathrm{mL}$ concentration of nanorods in $24 \mathrm{~h}$ of exposure gives the expected results, and at high concentration, greater percentage of cell death can be observed. This shows a positive approach in treating prostate cancer and other tumor treatment where taurine-modified nanorods can increase the aptness of the current cancer therapies with minimal side effects.

\section{CONCLUSIONS}

In the present work, we attempt to achieve the targeted action of taurine-immobilized pDA-coated iron oxide nanorods. Taurine is an important biomolecule that helps in improving the efficacy of the nanodelivery vehicles as it has the potential of crossing the BBB. The successful binding and functionalization of taurine and $\mathrm{pDA}$ on the iron oxide surfaces were proved using XPS data. A drug entrapment efficiency of $70.1 \%$ gave a 

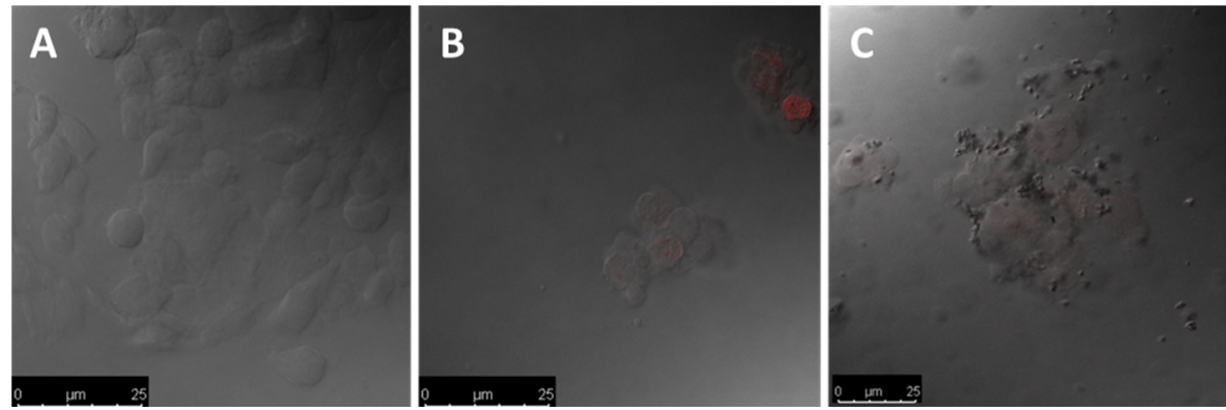

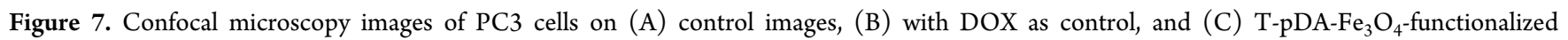
nanohybrid loaded with DOX.
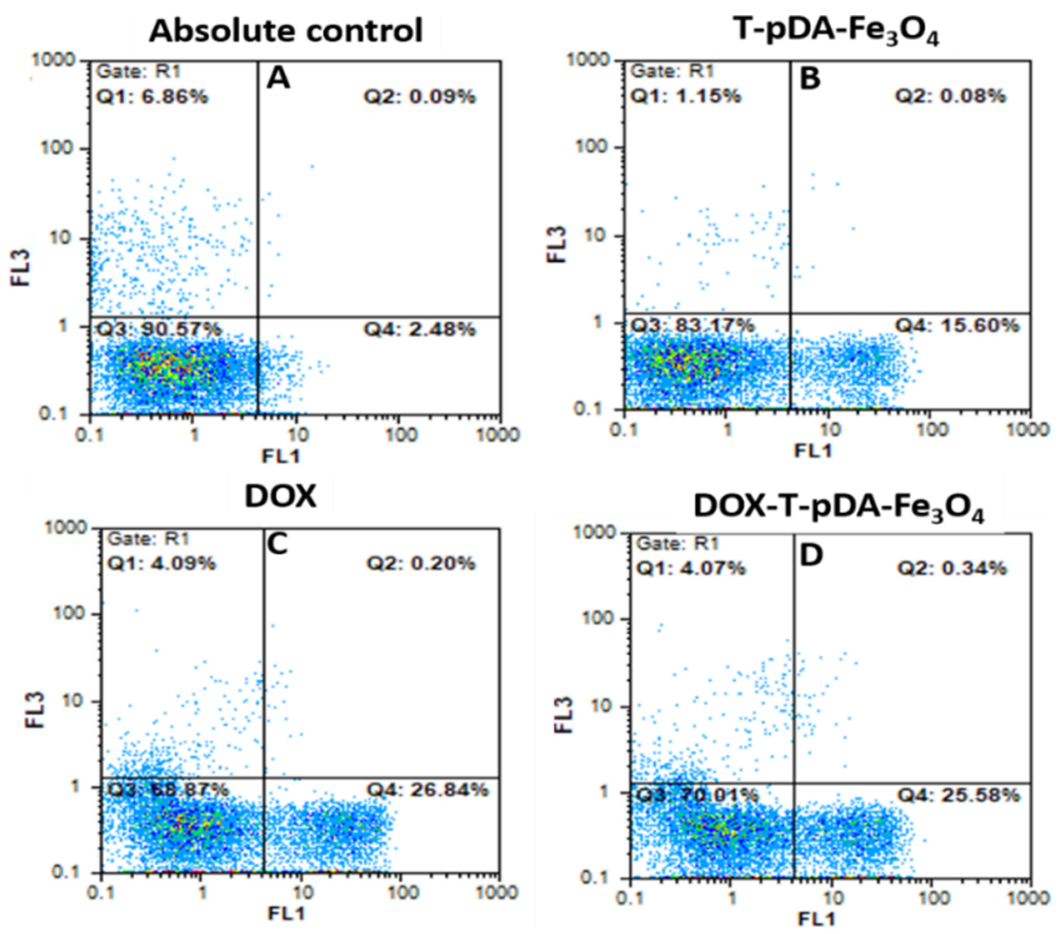

Figure 8. Cells apoptosis determined by Annexin V and PI staining of (A) absolute control, (B) T-pDA-Fe $\mathrm{O}_{4}$, (C) free drug, DOX, and (D) Doxloaded T-pDA- $\mathrm{Fe}_{3} \mathrm{O}_{4}$.

positive approach toward designing the nanovehicle for the cancer treatment. Additionally, on analyzing the drug release kinetics, it showed the $\mathrm{pH}$-dependent behavior of the nanovehicle, making it an efficient tool for the effective delivery in the tumor microenvironment.

In vitro studies based on the data obtained with the MTS assay, confocal microscopy images, and flow cytometry (Annexin V-FITC assay) on prostate carcinoma PC3 cells helped in evaluating the cellular response of the developed nanovehicle. It establishes that the developed nanovehicle has no side effect on the developed cell line when using DOX alone for the treatment. It also reveals the good cellular uptake of the developed nanohybrid that induced the cell death as of the free drug and can be successfully employed as a nanocarrier for the treatment of cancer cells. Conclusively, it shows the potential that overcomes the drawback of the conventional mode of cancer treatment and can be employed as an alternative tool for designing the nanovehicle.

\section{MATERIALS AND METHODS}

4.1. Chemicals and Reagents. Doxorubicin $\mathrm{HCl}, \mathrm{DA}$ $\mathrm{HCl}$, and taurine $(\mathrm{T})$ were obtained from Sigma-Aldrich (St. Louis, MO, USA). $\mathrm{NaOH}, \mathrm{HCl}(0.1 \mathrm{~N})$, anhydrous $\mathrm{FeCl}_{3}$, $\mathrm{FeSO}_{4} \cdot 7 \mathrm{H}_{2} \mathrm{O}$, sodium chloride $(\mathrm{NaCl})$, potassium chloride $(\mathrm{KCl})$, sodium hydrogen phosphate $\left(\mathrm{Na}_{2} \mathrm{HPO}_{4}\right)$, and potassium dihydrogen phosphate $\left(\mathrm{KH}_{2} \mathrm{PO}_{4}\right)$ for phosphatebuffered saline (PBS) buffer were used from Finar (India). Annexin V-FITC detection kit with PI staining for cell apoptosis was obtained from BD biosciences (Franklin Lakes, NJ, USA). All other chemicals were of analytical grade and used without further purification.

4.2. Preparation of Iron Oxide Nanorods Coated with DA. $\mathrm{Fe}_{3} \mathrm{O}_{4}$ nanoparticles were prepared as per our previous report ${ }^{79}$ with slight modifications. $\mathrm{FeCl}_{3}(0.02 \mathrm{M})$ and $\mathrm{FeSO}_{4}$. $7 \mathrm{H}_{2} \mathrm{O}(0.01 \mathrm{M})$ were first dissolved in $\mathrm{HCl}(200 \mathrm{~mL}$ of $1.2 \mathrm{mM}$ ) solution by ultrasound treatment. Then, IONP particles were precipitated from the solution by adding $1.25 \mathrm{M}$ aqueous $\mathrm{NaOH}$ solution $(300 \mathrm{~mL})$ dropwise under continuous shaking for at least $30 \mathrm{~min}$ in a $500 \mathrm{~mL}$ beaker. The black precipitate were washed with deionized (DI) water until the 
solution reached the $\mathrm{pH} 7$ and magnetically separated. The black color powder was then dried at $40{ }^{\circ} \mathrm{C}$ overnight.

DA was then grafted by dispersing nanoparticles $(500 \mathrm{mg})$ in $25 \mathrm{~mL}$ of $10 \mathrm{mM}$ DA solution (PBS, $\mathrm{pH} \mathrm{8.5)} \mathrm{for} 24 \mathrm{~h}$ under continuous shaking. ${ }^{80}$ DA undergoes a self-polymerization reaction to form $\mathrm{pDA}$, and the linkage developed on the surface of $\mathrm{Fe}_{3} \mathrm{O}_{4}$ is due to the chelation of the hydroxyl groups of DA on iron atoms, providing the stable nanoparticles. ${ }^{38}$ pDA-coated $\mathrm{Fe}_{3} \mathrm{O}_{4}$ nanorods $\left(\mathrm{pDA}-\mathrm{Fe}_{3} \mathrm{O}_{4}\right.$ ) were washed with DI water to ensure the complete removal of unreacted DA using magnetic decantation.

To conjugate taurine onto the surface of pDA- $\mathrm{Fe}_{3} \mathrm{O}_{4}$ nanorods, $50 \mathrm{mg}$ of as-prepared $\mathrm{pDA}-\mathrm{Fe}_{3} \mathrm{O}_{4}$ nanorods was dispersed in $1 \mathrm{mg} / \mathrm{mL}$ taurine solution ( $\mathrm{PBS}$ buffer, $\mathrm{pH}$ 7.4) for $24 \mathrm{~h}$ under continuous stirring at $25{ }^{\circ} \mathrm{C}$. The resulting nanorods $\left(\mathrm{T}-\mathrm{pDA}-\mathrm{Fe}_{3} \mathrm{O}_{4}\right.$ ) were washed with $\mathrm{DI}$ water under magnetic stirring, vacuum-dried, and stored under refrigeration for further analysis.

4.3. Drug Loading and Kinetics. DOX was loaded onto the developed $\mathrm{T}-\mathrm{pDA}-\mathrm{Fe}_{3} \mathrm{O}_{4}$ nanorods by covalent bonding where DOX $(0.8 \mathrm{mg} / \mathrm{mL})$ was added to the nanorods $(3.2 \mathrm{mg} / \mathrm{mL})$ suspended in DI water under continuous stirring for $24 \mathrm{~h}$ at $25{ }^{\circ} \mathrm{C}$. During the loading procedure, UV-vis spectra of the supernatant were recorded before and after the reaction to analyze the entrapment efficiency. After loading, the nanorods were separated from unreacted DOX using a strong magnet, and UV-vis spectra were recorded to ensure the complete removal of unreacted DOX. The developed drugloaded nanorods were then stored in PBS buffer $(10 \mathrm{mM}$, $\mathrm{pH}$ 7.4). Drug release kinetics were analyzed by using a double-diffusion method. The system was distributed in two regions: the donor which includes drug-loaded T-pDA- $\mathrm{Fe}_{3} \mathrm{O}_{4}$ nanorods and the receiver region with the PBS medium at the required $\mathrm{pH}$. The region was separated with a dialysis membrane $(12-14 \mathrm{kDa})$ holding the nanorods in it. DOX is expected to pass through the membrane and thus, after each interval, the PBS medium was withdrawn from the receiver chamber and analyzed using UV-vis and fluorescence spectroscopy by measuring the fluorescence intensity with an excitation wavelength $\left(\lambda_{\mathrm{ex}}\right)=470 \mathrm{~nm}$ and an emission wavelength $\left(\lambda_{\mathrm{em}}\right)=590 \mathrm{~nm}$ with excitation slit $(\mathrm{nm})=5$ and emission slit $(\mathrm{nm})=10$. A standard calibration curve of DOX was plotted to quantify the loading kinetics from our previously reported method (data not shown). ${ }^{81}$ The release studies were analyzed at different $\mathrm{pH}$ of the PBS medium to check the efficiency of the drug release in the biological and tumor conditions.

4.4. Characterization Techniques. The chemical composition and morphology of the developed nanorods were analyzed using TEM with EDX and XPS analysis. TEM is a Tecnai G 220 (FEI) S-Twin transmission electron microscope operating at $200 \mathrm{kV}$. The equipment provides a line resolution of $0.14 \mathrm{~nm}$, and EDX gives the elemental composition of the material. Samples for TEM were prepared using diluted suspension of NPs in deionized water on a carbon-coated $\mathrm{Cu}$ grid after air drying. The average size of nanoparticles was calculated on each sample (100 nanoparticles) using ImageJ software.

XPS was performed using Omicron ESCA (Electron Spectroscope for Chemical Analysis) from Oxford Instrument (Germany). An $\mathrm{Al}$ anode of energy $1486.7 \mathrm{eV}$ was used for analyzing samples, with an acquisition time of $0.1 \mathrm{~s}$. CasaXPS software was used to analyze the data. Carbon C 1s peak at
$284.5 \mathrm{eV}$ was used as the reference in the neutralization to minimize the charge effects, and Gauss (70\%)-Lorentz (30\%) profiles were used after subtracting a Shirley background. Full width at half-maximum was fixed between 1.4 and $1.6 \mathrm{eV}$ for $\mathrm{O} 1 \mathrm{~s}, 1.6$ and $1.7 \mathrm{eV}$ for $\mathrm{C} 1 \mathrm{~s}$, and 1.7 and $1.8 \mathrm{eV}$ for $\mathrm{N} 1 \mathrm{~s}$.

To confirm the functionalization by DA and immobilization of taurine over the nanorods, attenuated total reflectance FTIR spectroscopy measurements were performed using a Schimadzu 8400 s spectrophotometer with the range of $4000-400 \mathrm{~cm}^{-1}$ and a resolution of $4 \mathrm{~cm}^{-1}$ with the total of 45 scans per measurement.

UV-visible studies were done to study the absorbance of the as-prepared nanorods and drug kinetics using a Cary 50 Varian UV-vis spectrophotometer. All of the spectra were measured between $400 \mathrm{~nm}$ and $800 \mathrm{~nm}$ at $25^{\circ} \mathrm{C}$ using a quartz cuvette of $1 \mathrm{~cm}$ path length.

Drug release kinetics was analyzed by fluorescence spectroscopy using a Cary Eclipse fluorescent spectrophotometer in the emission range of $380-700 \mathrm{~nm}$. The selected excitation and emission slits were $5 \mathrm{~nm}$ and $10 \mathrm{~nm}$.

The hydrodynamic diameter was determined using Malvern Zetasizer NanoZSP90 (Malvern, UK) supplied by a DTS Nano V7.11 software. The suspensions of IONPs were ultrasonicated $\left(15 \mathrm{~min}\right.$ ) and prepared using $10^{-2} \mathrm{M} \mathrm{NaCl}$ aqueous solutions. The $\mathrm{pH}$ of the suspension was adjusted from 3 to 11 by the addition of $\mathrm{HCl}(0.1 \mathrm{M})$ or $\mathrm{NaOH}(0.1$ and $0.01 \mathrm{M})$ solutions. Hydrodynamic diameters were determined by DLS curves which were derived from the number distribution calculation on the same instrument.

4.5. Biological Assays. In vitro assays on PC-3 cell line (human caucasian prostate adenocarcinoma cells) were used to measure the cytotoxicity. The cells were seeded in 96-well plates having a concentration of 3000 cells/well, followed by incubation at $37{ }^{\circ} \mathrm{C}$ in $190 \mu \mathrm{L}$ of drug-free culture medium (DMEM) with $10 \%$ foetal bovine serum for $24 \mathrm{~h}$ prior to the treatment (until 20\% confluence). Tumor cells were then incubated ( $+10 \mu \mathrm{L}$ of drug on $190 \mu \mathrm{L}$ of culture medium) with equivalent range of drug concentrations. Cell viability was measured after $48 \mathrm{~h}$ incubation using MTS assay (Promega Corporation, USA) according to Mirjolet et al. ${ }^{82}$ All of the experiments were performed three times for the precise results, and the data were calculated as the mean of the measurements.

Cell death characterization of DOX-loaded nanorods was studied using the flow cytometry method where the proportion of cell in apoptosis was measured. In six-well plates, PC-3 cells were exposed to the tested samples ( $\mathrm{T}-\mathrm{pDA}-\mathrm{Fe}_{3} \mathrm{O}_{4}$ and DOX$\mathrm{T}$-pDA- $\mathrm{Fe}_{3} \mathrm{O}_{4}$ ) after $24 \mathrm{~h}$ of incubation plus a negative control well for $24 \mathrm{~h}$. A double staining with annexin V-FITC and PI was performed after the treatment along with the FITC Annexin V apoptosis detection kit. The cells were washed twice in DPBS (PBS without $\mathrm{Ca}^{2+}$ and $\mathrm{Mg}^{2+}$ ) and then trypsinized with trypsin solution $(1 \mathrm{~mL}, 1 \times)$ after which it was centrifuged for $5 \mathrm{~min}$ at $300 \mathrm{~g}$. It was then washed with cold PBS and $1 \mathrm{~mL}$ of annexin $\mathrm{V}$ binding buffer $(1 \times) ; 10 \mu \mathrm{L}$ of FITC and $10 \mu \mathrm{L}$ of PI staining solutions were added to each sample. Finally, cells were incubated for $15 \mathrm{~min}$ at $37^{\circ} \mathrm{C}$. Cell suspensions were analyzed with a Galaxy flow cytometer (Partec). The red fluorescence of PI was collected through a $590 \mathrm{~nm}$ long-pass filter, and the green fluorescence was collected through a $520 \mathrm{~nm}$ band-pass filter. For each sample, 10,000 cells were analyzed, and the data were investigated with Flow (Tree Star Inc.) software. 


\section{ASSOCIATED CONTENT}

\section{(1) Supporting Information}

The Supporting Information is available free of charge at https://pubs.acs.org/doi/10.1021/acsomega.0c01747.

EDX spectra showing the elemental composition of $\mathrm{Fe}_{3} \mathrm{O}_{4}$ nanoparticles, pDA- $\mathrm{Fe}_{3} \mathrm{O}_{4}$ nanorods, T-pDA$\mathrm{Fe}_{3} \mathrm{O}_{4}$ nanorods and elemental mapping of the nanoparticles; XPS fitted spectra; DLS spectra showing the size distribution of $\mathrm{Fe}_{3} \mathrm{O}_{4}$ nanoparticles, pDA- $\mathrm{Fe}_{3} \mathrm{O}_{4}$ nanorods, and $\mathrm{T}-\mathrm{pDA}-\mathrm{Fe}_{3} \mathrm{O}_{4}$ nanorods; and different binding energies observed from XPS showing various functional groups with calculated area \% (PDF)

\section{AUTHOR INFORMATION}

\section{Corresponding Authors}

Nadine Millot - Laboratoire Interdisciplinaire Carnot de Bourgogne, UMR 6303 CNRS/Universite Bourgogne FrancheComte, Dijon 21078, France; (1) orcid.org/0000-0002-01273858; Email: nmillot@u-bourgogne.fr

Rajender Kumar - Department of Applied Chemistry, S. V. National Institute of Technology, Surat 395007, Gujarat, India; Department of Chemistry and Chemical Science, School of Physical and Material Sciences, Central University of Himachal Pradesh, Kangra, Himachal Pradesh 176215, India; ○ orcid.org/0000-0002-5817-2046; Email: rajender@ cuhimachal.ac.in, rajenderkumar@chem.svnit.ac.in

\section{Authors}

Nimisha Singh - Department of Applied Chemistry, S. V. National Institute of Technology, Surat 395007, Gujarat, India; Laboratoire Interdisciplinaire Carnot de Bourgogne, UMR 6303 CNRS/Université Bourgogne Franche-Comté, Dijon 21078, France

Lionel Maurizi - Laboratoire Interdisciplinaire Carnot de Bourgogne, UMR 6303 CNRS/Universite Bourgogne FrancheComté, Dijon 21078, France

Gérard Lizard - Laboratory Bio-PeroxIL, EA7270, Université Bourgogne Franche-Comté/Inserm, Dijon 21000, France

Complete contact information is available at:

https://pubs.acs.org/10.1021/acsomega.0c01747

\section{Funding}

This project was successfully completed with the financial supported received by the grant of SVNIT, Surat (Fellowship to N.S.), and SERB New Delhi (YSS/2015/001184). This work is also part of the project "Pharmacoimagerie et agents théranostiques", funded by the "Universite de Bourgogne" and the "Conseil Régional de Bourgogne" through the "Plan d'Actions Régional pour l'Innovation (PARI)" and the European Union through the PO FEDER-FSE Bourgogne 2014/2020 programs. This work has been also supported by the EIPHI Graduate School (contract ANR-17-EURE-0002).

\section{Notes}

The authors declare no competing financial interest.

${ }^{\perp}$ The author is on lien from S. V. National Institute of Technology to Central University of Himachal Pradesh.

\section{ACKNOWLEDGMENTS}

We would like to further acknowledge MNIT Jaipur for providing us facilities such as HR-TEM and XPS. The authors would also like to thank Dr. Fadoua Sallem (ICB), and Dr. Julien Boudon (ICB), for their help in some experiments and
Dr. Véronique Morgand (CGFL), Dr. Céline Mirjolet (CGFL), Christine Arnould (DImaCell), and Thomas Nury (BioPeroxIL lab) for in vitro investigations.

\section{REFERENCES}

(1) Cai, W.; Gao, T.; Hong, H.; Sun, J. Applications of gold nanoparticles in cancer nanotechnology. Nanotechnol., Sci. Appl. 2008, 1,17 .

(2) Stewart, B. W.; Kleihues, P. World Cancer Report; IARC Press Lyon, 2003; Vol. 57.

(3) Peer, D.; Karp, J. M.; Hong, S.; Farokhzad, O. C.; Margalit, R.; Langer, R. Nanocarriers as an emerging platform for cancer therapy. Nat. Nanotechnol. 2007, 2, 751.

(4) Brannon-Peppas, L.; Blanchette, J. O. Nanoparticle and targeted systems for cancer therapy. Adv. Drug Delivery Rev. 2012, 64, 206212.

(5) Torchilin, V. P. Drug targeting. Eur. J. Pharm. Sci. 2000, 11, S81-S91.

(6) Schreier, H. Drug Targeting Technology: Physical Chemical Biological Methods; CRC Press, 2016; pp 1-294.

(7) Schlenoff, J. B. Zwitteration: Coating Surfaces with Zwitterionic Functionality to Reduce Nonspecific Adsorption. Langmuir 2014, 30, 9625-9636.

(8) Neuberger, T.; Schöpf, B.; Hofmann, H.; Hofmann, M.; Von Rechenberg, B. Superparamagnetic nanoparticles for biomedical applications: possibilities and limitations of a new drug delivery system. J. Magn. Magn. Mater. 2005, 293, 483-496.

(9) Zhang, J.; Misra, R. D. K. Magnetic drug-targeting carrier encapsulated with thermosensitive smart polymer: core-shell nanoparticle carrier and drug release response. Acta Biomater. 2007, 3, 838-850.

(10) Jain, T. K.; Reddy, M. K.; Morales, M. A.; Leslie-Pelecky, D. L.; Labhasetwar, V. Biodistribution, clearance, and biocompatibility of iron oxide magnetic nanoparticles in rats. Mol. Pharmaceutics 2008, 5, 316-327.

(11) Revia, R. A.; Zhang, M. Magnetite nanoparticles for cancer diagnosis, treatment, and treatment monitoring: recent advances. Mater. Today Chem. 2016, 19, 157-168.

(12) Senapati, S.; Mahanta, A. K.; Kumar, S.; Maiti, P. Controlled drug delivery vehicles for cancer treatment and their performance. Signal Transduction Targeted Ther. 2018, 3, 7.

(13) Arias, L.; Pessan, J.; Vieira, A.; Lima, T.; Delbem, A.; Monteiro, D. Iron Oxide Nanoparticles for Biomedical Applications: A Perspective on Synthesis, Drugs, Antimicrobial Activity, and Toxicity. Antibiot 2018, 7, 46.

(14) Ray, P. C. Size and shape dependent second order nonlinear optical properties of nanomaterials and their application in biological and chemical sensing. Chem. Rev. 2010, 110, 5332-5365.

(15) Maurizi, L.; Papa, A.-L.; Dumont, L.; Bouyer, F.; Walker, P.; Vandroux, D.; Millot, N. Influence of surface charge and polymer coating on internalization and biodistribution of polyethylene glycolmodified iron oxide nanoparticles. J. Biomed. Nanotechnol. 2015, 11, 126-136.

(16) Papa, A.-L.; Dumont, L.; Vandroux, D.; Millot, N. Titanate nanotubes: towards a novel and safer nanovector for cardiomyocytes. Nanotoxicology 2012, 7, 1131-1142.

(17) Gratton, S. E. A.; Ropp, P. A.; Pohlhaus, P. D.; Luft, J. C.; Madden, V. J.; Napier, M. E.; DeSimone, J. M. The effect of particle design on cellular internalization pathways. Proc. Natl. Acad. Sci. U.S.A. 2008, 105, 11613-11618.

(18) Albanese, A.; Tang, P. S.; Chan, W. C. W. The effect of nanoparticle size, shape, and surface chemistry on biological systems. Annu. Rev. Biomed. Eng. 2012, 14, 1-16.

(19) Geng, Y.; Dalhaimer, P.; Cai, S.; Tsai, R.; Tewari, M.; Minko, T.; Discher, D. E. Shape effects of filaments versus spherical particles in flow and drug delivery. Nat. Nanotechnol. 2007, 2, 249.

(20) Nath, S.; Kaittanis, C.; Ramachandran, V.; Dalal, N. S.; Perez, J. M. Synthesis, Magnetic Characterization, and Sensing Applications of 
Novel Dextran-Coated Iron Oxide Nanorods. Chem. Mater. 2009, 21, 1761-1767.

(21) Loiseau, A.; Boudon, J.; Mirjolet, C.; Créhange, G.; Millot, N. Taxane-Grafted Metal-Oxide Nanoparticles as a New Theranostic Tool against Cancer: The Promising Example of Docetaxel-Functionalized Titanate Nanotubes on Prostate Tumors. Adv. Healthcare Mater. 2017, 6, 1700245.

(22) Black, K. C.; Yi, J.; Rivera, J. G.; Zelasko-Leon, D. C.; Messersmith, P. B. Polydopamine-enabled surface functionalization of gold nanorods for cancer cell-targeted imaging and photothermal therapy. Nanomedicine 2013, 8, 17-28.

(23) Patel, K.; Singh, N.; Yadav, J.; Nayak, J. M.; Sahoo, S. K.; Lata, J.; Chand, D.; Kumar, S.; Kumar, R. Polydopamine films change their physicochemical and antimicrobial properties with a change in reaction conditions. Phys. Chem. Chem. Phys. 2018, 20, 5744-5755.

(24) Ye, Q.; Zhou, F.; Liu, W. Bioinspired catecholic chemistry for surface modification. Chem. Soc. Rev. 2011, 40, 4244-4258.

(25) Turcheniuk, K.; Tarasevych, A. V.; Kukhar, V. P.; Boukherroub, R.; Szunerits, S. Recent advances in surface chemistry strategies for the fabrication of functional iron oxide based magnetic nanoparticles. Nanoscale 2013, 5, 10729-10752.

(26) Singh, N.; Sallem, F.; Mirjolet, C.; Nury, T.; Sahoo, S. K.; Millot, N.; Kumar, R. Polydopamine Modified Superparamagnetic Iron Oxide Nanoparticles as Multifunctional Nanocarrier for Targeted Prostate Cancer Treatment. Nanomaterials 2019, 9, 138.

(27) Lin, L.-S.; Cong, Z.-X.; Cao, J.-B.; Ke, K.-M.; Peng, Q.-L.; Gao, J.; Yang, H.-H.; Liu, G.; Chen, X. Multifunctional Fe3O4@ Polydopamine Core-Shell Nanocomposites for Intracellular mRNA Detection and Imaging-Guided Photothermal Therapy. ACS Nano 2014, 8, 3876-3883.

(28) Wu, L.; Zhang, F.; Wei, Z.; Li, X.; Zhao, H.; Lv, H.; Ge, R.; Ma, H.; Zhang, H.; Yang, B. Magnetic delivery of Fe3O4@polydopamine nanoparticle-loaded natural killer cells suggest a promising anticancer treatment. Biomater. Sci. 2018, 6, 2714-2725.

(29) Dreyer, D. R.; Miller, D. J.; Freeman, B. D.; Paul, D. R.; Bielawski, C. W. Elucidating the structure of poly(dopamine). Langmuir 2012, 28, 6428-6435.

(30) Suominen, T.; Piepponen, T. P.; Kostiainen, R. Permeation of dopamine sulfate through the blood-brain barrier. PLoS One 2015, 10, No. e0133904.

(31) Kang, Y.-S.; Ohtsuki, S.; Takanaga, H.; Tomi, M.; Hosoya, K.-i.; Terasaki, T. Regulation of taurine transport at the blood-brain barrier by tumor necrosis factor- $\alpha$, taurine and hypertonicity. J. Neurochem. 2002, 83, 1188-1195.

(32) Wu, M.; Zhang, D.; Zeng, Y.; Wu, L.; Liu, X.; Liu, J. Nanocluster of superparamagnetic iron oxide nanoparticles coated with poly (dopamine) for magnetic field-targeting, highly sensitive MRI and photothermal cancer therapy. Nanotechnology 2015, 26, 115102.

(33) Dawson, R.; Baker, D.; Eppler, B.; Tang, E.; Shih, D.; Hern, H.; $\mathrm{Hu}, \mathrm{M}$. Taurine inhibition of metal-stimulated catecholamine oxidation. Neurotoxic. Res. 2000, 2, 1-15.

(34) Cornell, R. M.; Schwertmann, U. The Iron Oxides: Structure, Properties, Reactions, Occurrences and Uses; John Wiley \& Sons, 2003; pp $1-267$.

(35) He, Y. T.; Traina, S. J. Transformation of magnetite to goethite under alkaline $\mathrm{pH}$ conditions. Clay Miner. 2007, 42, 13-19.

(36) Qu, H.; Caruntu, D.; Liu, H.; O’Connor, C. J. Water-dispersible iron oxide magnetic nanoparticles with versatile surface functionalities. Langmuir 2011, 27, 2271-2278.

(37) Barras, A.; Lyskawa, J.; Szunerits, S.; Woisel, P.; Boukherroub, R. Direct functionalization of nanodiamond particles using dopamine derivatives. Langmuir 2011, 27, 12451-12457.

(38) Mazur, M.; Barras, A.; Kuncser, V.; Galatanu, A.; Zaitzev, V.; Turcheniuk, K. V.; Woisel, P.; Lyskawa, J.; Laure, W.; Siriwardena, A.; Boukherroub, R.; Szunerits, S. Iron oxide magnetic nanoparticles with versatile surface functions based on dopamine anchors. Nanoscale 2013, 5, 2692-2702.
(39) Thakur, V. K.; Vennerberg, D.; Madbouly, S. A.; Kessler, M. R. Bio-inspired green surface functionalization of PMMA for multifunctional capacitors. RSC Adv. 2014, 4, 6677-6684.

(40) Mazur, M.; Barras, A.; Kuncser, V.; Galatanu, A.; Zaitzev, V.; Turcheniuk, K. V.; Woisel, P.; Lyskawa, J.; Laure, W.; Siriwardena, A.; Boukherroub, R.; Szunerits, S. Iron oxide magnetic nanoparticles with versatile surface functions based on dopamine anchors. Nanoscale 2013, 5, 2692-2702

(41) Chapter 5-Sulfoxides, Sulfones, Sulfates, Monothiosulfates, Sulfonyl Halides, Sulfites, Sulfonamides, Sulfonates, and N-Sulfinyl Anilines. In Interpreting Infrared, Raman, and Nuclear Magnetic Resonance Spectra; Nyquist, R. A., Ed.; Academic Press: San Diego, 2001; pp 85-117.

(42) Jiang, W.; Lai, K.-L.; Hu, H.; Zeng, X.-B.; Lan, F.; Liu, K.-X.; Wu, Y.; Gu, Z.-W. The effect of [Fe 3+]/[Fe 2+] molar ratio and iron salts concentration on the properties of superparamagnetic iron oxide nanoparticles in the water/ethanol/toluene system. J. Nanopart. Res. 2011, 13, 5135 .

(43) Perriat, P.; Fries, E.; Millot, N.; Domenichini, B. XPS and EELS investigations of chemical homogeneity in nanometer scaled Tiferrites obtained by soft chemistry. Solid State Ionics 1999, 117, 175184.

(44) Thomas, G.; Demoisson, F.; Boudon, J.; Millot, N. Efficient functionalization of magnetite nanoparticles with phosphonate using a one-step continuous hydrothermal process. Dalton Trans. 2016, 45, $10821-10829$.

(45) Thomas, G.; Demoisson, F.; Chassagnon, R.; Popova, E.; Millot, N. One-step continuous synthesis of functionalized magnetite nanoflowers. Nanotechnology 2016, 27, 135604.

(46) Mullet, M.; Khare, V.; Ruby, C. XPS study of Fe(II)-Fe(III) (oxy)hydroxycarbonate green rust compounds. Surf. Interface Anal. 2008, 40, 323-328.

(47) Zangmeister, R. A.; Morris, T. A.; Tarlov, M. J. Characterization of polydopamine thin films deposited at short times by autoxidation of dopamine. Langmuir 2013, 29, 8619-8628.

(48) Amstad, E.; Gehring, A. U.; Fischer, H.; Nagaiyanallur, V. V.; Hähner, G.; Textor, M.; Reimhult, E. Influence of Electronegative Substituents on the Binding Affinity of Catechol-Derived Anchors to Fe3O4 Nanoparticles. J. Phys. Chem. C 2011, 115, 683-691.

(49) Harrington, M. J.; Masic, A.; Holten-Andersen, N.; Waite, J. H.; Fratzl, P. Iron-clad fibers: a metal-based biological strategy for hard flexible coatings. Science 2010, 328, 216-220.

(50) Dreyer, D. R.; Miller, D. J.; Freeman, B. D.; Paul, D. R.; Bielawski, C. W. Elucidating the structure of poly(dopamine). Langmuir 2012, 28, 6428-6435.

(51) Lee, H.; Dellatore, S. M.; Miller, W. M.; Messersmith, P. B. Mussel-inspired surface chemistry for multifunctional coatings. Science 2007, 318, 426-430.

(52) Hong, S.; Kim, K. Y.; Wook, H. J.; Park, S. Y.; Lee, K. D.; Lee, D. Y.; Lee, H. Attenuation of the in vivo toxicity of biomaterials by polydopamine surface modification. Nanomedicine 2011, 6, 793-801.

(53) d'Ischia, M.; Napolitano, A.; Pezzella, A.; Meredith, P.; Sarna, T. Chemical and structural diversity in eumelanins: unexplored biooptoelectronic materials. Angew. Chem., Int. Ed. 2009, 48, 3914-3921.

(54) Wagner AVN, C. D.; Kraut-Vass, A.; Allison, J. W.; Powell, C. J.; Rumble, J. R., Jr. NIST Standard Reference Database 20, version 3.4 (http:/srdata.nist.gov/xps/), 2003.

(55) Umamaheswari, V.; Böhlmann, W.; Pöppl, A.; Vinu, A.; Hartmann, M. Spectroscopic characterization of iron-containing MCM-58. Microporous Mesoporous Mater. 2006, 89, 47-57.

(56) Bordiga, S.; Buzzoni, R.; Geobaldo, F.; Lamberti, C.; Giamello, E.; Zecchina, A.; Leofanti, G.; Petrini, G.; Tozzola, G.; Vlaic, G. Structure and reactivity of framework and extraframework iron in $\mathrm{Fe}-$ silicalite as investigated by spectroscopic and physicochemical methods. J. Catal. 1996, 158, 486-501.

(57) Yildirim, A.; Bayindir, M. Turn-on fluorescent dopamine sensing based on in situ formation of visible light emitting polydopamine nanoparticles. Anal. Chem. 2014, 86, 5508-5512. 
(58) Shultz, M. D.; Reveles, J. U.; Khanna, S. N.; Carpenter, E. E. Reactive nature of dopamine as a surface functionalization agent in iron oxide nanoparticles. J. Am. Chem. Soc. 2007, 129, 2482-2487.

(59) Tang, L.; Mo, S.; Liu, S. G.; Liao, L. L.; Li, N. B.; Luo, H. Q. Synthesis of fluorescent polydopamine nanoparticles by Michael addition reaction as an analysis platform to detect iron ions and pyrophosphate efficiently and construction of an IMPLICATION logic gate. Sens. Actuators, B 2018, 255, 754-762.

(60) Gasymov, O. K.; Glasgow, B. J. ANS fluorescence: potential to augment the identification of the external binding sites of proteins. Biochim. Biophys. Acta, Proteins Proteomics 2007, 1774, 403-411.

(61) Meredith, P.; Powell, B. J.; Riesz, J.; Nighswander-Rempel, S. P.; Pederson, M. R.; Moore, E. G. Towards structure-propertyfunction relationships for eumelanin. Soft Matter 2006, 2, 37-44.

(62) Kwon, H.; Lee, K.; Kim, H.-J. Coumarin-malonitrile conjugate as a fluorescence turn-on probe for biothiols and its cellular expression. Chem. Commun. 2011, 47, 1773-1775.

(63) Zhang, X.; Wang, S.; Xu, L.; Feng, L.; Ji, Y.; Tao, L.; Li, S.; Wei, Y. Biocompatible polydopamine fluorescent organic nanoparticles: facile preparation and cell imaging. Nanoscale 2012, 4, 5581-5584.

(64) Yu, X.; Fan, H.; Liu, Y.; Shi, Z.; Jin, Z. Characterization of Carbonized Polydopamine Nanoparticles Suggests Ordered Supramolecular Structure of Polydopamine. Langmuir 2014, 30, 54975505.

(65) Chouhan, R.; Bajpai, A. Real time in vitro studies of doxorubicin release from PHEMA nanoparticles. J. Nanobiotechnol. 2009, 7, 5.

(66) Awotwe-Otoo, D.; Zidan, A. S.; Rahman, Z.; Habib, M. J. Evaluation of Anticancer Drug-Loaded Nanoparticle Characteristics by Nondestructive Methodologies. AAPS PharmSciTech 2012, 13, 611-622.

(67) Verma, G.; Shetake, N. G.; Barick, K. C.; Pandey, B. N.; Hassan, P. A.; Priyadarsini, K. I. Covalent immobilization of doxorubicin in glycine functionalized hydroxyapatite nanoparticles for $\mathrm{pH}$-responsive release. New J. Chem. 2018, 42, 6283-6292.

(68) Kang, S. I.; Na, K.; Bae, Y. H. Sulfonamide-containing polymers: a new class of $\mathrm{pH}$-sensitive polymers and gels. Macromol. Symp. 2001, 172, 149-156.

(69) Wang, C.; Xu, H.; Liang, C.; Liu, Y.; Li, Z.; Yang, G.; Cheng, L.; Li, Y.; Liu, Z. Iron Oxide @ Polypyrrole Nanoparticles as a Multifunctional Drug Carrier for Remotely Controlled Cancer Therapy with Synergistic Antitumor Effect. ACS Nano 2013, 7, 6782-6795.

(70) Topacli, C.; Topacli, A. Infrared spectra simulation for some sulfonamides by using semi-empirical methods. Spectrosc. Lett. 2002, 35, 207-217.

(71) Das, G.; Nicastri, A.; Coluccio, M. L.; Gentile, F.; Candeloro, P.; Cojoc, G.; Liberale, C.; De Angelis, F.; Di Fabrizio, E. FT-IR, Raman, RRS measurements and DFT calculation for doxorubicin. Microsc. Res. Tech. 2010, 73, 991-995.

(72) Shalviri, A.; Raval, G.; Prasad, P.; Chan, C.; Liu, Q.; Heerklotz, H.; Rauth, A. M.; Wu, X. Y. pH-Dependent doxorubicin release from terpolymer of starch, polymethacrylic acid and polysorbate 80 nanoparticles for overcoming multi-drug resistance in human breast cancer cells. Eur. J. Pharm. Biopharm. 2012, 82, 587-597.

(73) Yuan, Z.; Li, X.; Hu, J.; Xu, W.; Cao, J.; Zhang, H. Degradation mechanism of sulfonated poly (ether ether ketone)(SPEEK) ion exchange membranes under vanadium flow battery medium. Phys. Chem. Chem. Phys. 2014, 16, 19841-19847.

(74) Mi, P. Stimuli-responsive nanocarriers for drug delivery, tumor imaging, therapy and theranostics. Theranostics 2020, 10, 4557-4588.

(75) Tannock, I. F.; Rotin, D. Acid pH in tumors and its potential for therapeutic exploitation. Cancer Res. 1989, 49, 4373-4384.

(76) Zhao, X.; Liu, L.; Li, X.; Zeng, J.; Jia, X.; Liu, P. Biocompatible graphene oxide nanoparticle-based drug delivery platform for tumor microenvironment-responsive triggered release of doxorubicin. Langmuir 2014, 30, 10419-10429.
(77) Zhang, H.; Liu, J.; Chen, Q.; Mi, P. Ligand-installed anti-VEGF genomic nanocarriers for effective gene therapy of primary and metastatic tumors. J. Controlled Release 2020, 320, 314-327.

(78) He, X.; Dong, Y.; Wu, C. W.; Zhao, Z.; Ng, S. S. M.; Chan, F. K. L.; Sung, J. J. Y.; Yu, J. MicroRNA-218 inhibits cell cycle progression and promotes apoptosis in colon cancer by downregulating BMI1 polycomb ring finger oncogene. Mol. Med. 2012, 18, 1491.

(79) Singh, N.; Patel, K.; Sahoo, S. K.; Kumar, R. Human nitric oxide biomarker as potential NO donor in conjunction with superparamagnetic iron oxide@gold core shell nanoparticles for cancer therapeutics. Colloids Surf., B 2018, 163, 246-256.

(80) Martín, M.; Salazar, P.; Villalonga, R.; Campuzano, S.; Pingarrón, J. M.; González-Mora, J. L. Preparation of core-shell $\mathrm{Fe}_{3} \mathrm{O}_{4} @$ poly(dopamine) magnetic nanoparticles for biosensor construction. J. Mater. Chem. B 2014, 2, 739-746.

(81) Singh, N.; Nayak, J.; Sahoo, S. K.; Kumar, R. Glutathione conjugated superparamagnetic $\mathrm{Fe}_{3} \mathrm{O}_{4}$-Au core shell nanoparticles for $\mathrm{pH}$ controlled release of DOX. Mater. Sci. Eng., C 2019, 100, 453465 .

(82) Mirjolet, J.-F.; Barberi-Heyob, M.; Merlin, J.-L.; Marchal, S.; Etienne, M.-C.; Milano, G.; Bey, P. Thymidylate synthase expression and activity: relation to $S$-phase parameters and 5-fluorouracil sensitivity. Br. J. Cancer 1998, 78, 62. 